\title{
Theoretical foundations of the Study of Latino (SOL) Youth: implications for obesity and cardiometabolic risk
}

\author{
Guadalupe X. Ayala, PhD, MPHa, ${ }^{a}$, Mercedes Carnethon, $\mathrm{PhD}^{\mathrm{b}}$, Elva Arredondo, $\mathrm{PhD}^{\mathrm{a}}$, Alan \\ M. Delamater, PhD $^{c}$, Krista Perreira, PhD ${ }^{d}$, Linda Van Horn, PhD, RD ${ }^{b}$, John H. Himes, PhD, \\ MPH $^{e}$, John H. Eckfeldt, MD, PhD ${ }^{f}$, Shrikant I. Bangdiwala, PhD $^{g}$, Daniel A. Santisteban, \\ PhD $^{h}$, and Carmen R. Isasi, MD, PhD ${ }^{i}$ \\ a Division of Health Promotion and Behavioral Science, Graduate School of Public Health, San \\ Diego State University, San Diego, CA and the Institute for Behavioral and Community Health, \\ San Diego State University, San Diego, CA \\ b Department of Preventive Medicine, Feinberg School of Medicine, Northwestern University, \\ Chicago, IL \\ c Department of Pediatrics, University of Miami Miller School of Medicine, Miami, FL \\ d Department of Public Policy, University of North Carolina at Chapel Hill \\ e Division of Epidemiology and Community Health, University of Minnesota School of Public \\ Health, Minneapolis \\ f Department of Lab Medicine and Pathology, University of Minnesota, Minneapolis, MN \\ g Collaborative Studies Coordinating Center, Department of Biostatistics, Gillings School of \\ Global Public Health, University of North Carolina at Chapel Hill. \\ h School of Nursing and Health Sciences, University of Miami, Miami, FL \\ i Department of Epidemiology and Population Health, Albert Einstein College of Medicine, Bronx, \\ NY
}

\section{Abstract \\ Purpose-This article describes the conceptual model developed for the Hispanic Community Health Study/Study of Latino Youth, a multisite epidemiologic study of obesity and cardiometabolic risk among U.S. Hispanic/Latino children.}

\begin{abstract}
Methods-Public health, psychology, and sociology research were examined for relevant theories and paradigms. This research, in turn, led us to consider several study design features to best represent both risk and protective factors from multiple levels of influence, as well as the identification of culturally relevant scales to capture identified constructs.
\end{abstract}

Results-The Socio-Ecological Framework, Social Cognitive Theory, family systems theory, and acculturation research informed the specification of our conceptual model. Data are being collected from both children and parents in the household to examine the bidirectional influence of children and their parents, including the potential contribution of intergenerational differences in acculturation as a risk factor. Children and parents are reporting on individual, interpersonal, and

\footnotetext{
(C) 2013 Elsevier Inc. All rights reserved.

* Corresponding author. San Diego State University and the Institute for Behavioral and Community Health, 9245 Sky Park Court, Suite 220, San Diego, CA 92123. Tel: 619-594-6686; Fax: 619-594-2998. ayala@ mail.sdsu.edu (G.X. Ayala)..
} 
perceived organizational and community influences on children's risk for obesity consistent with Socio-Ecological Framework.

Conclusions-Much research has been conducted on obesity, yet conceptual models examining risk and protective factors lack specificity in several areas. Study of Latino Youth is designed to fill a gap in this research and inform future efforts.

\section{Keywords}

Hispanic/Latino; Children; Obesity; Acculturation; Socio-Ecological Framework; Theory

\section{Introduction}

The problem of childhood obesity continues in the United States, with a prevalence of $31 \%$ among the general population of children aged 6-19 years [1]. Mexican-American boys aged 12-19 years are among the highest at risk for being obese (49\%), followed closely by other Hispanic/Latino boys aged 12-19 years (46\%). Studies examining differences by specific Hispanic/Latino background in the United States are lacking, although evidence from Latin America suggests that among adults, Mexicans have the highest prevalence rates followed by residents of Central America [2]. Research to better understand sources of influence are sorely needed, given the numerous negative implications of childhood obesity, including adult obesity [3], associated comorbidities [4], compromises in quality of life [5], and early mortality [6]. The Study of Latino (SOL) Youth study is designed to fill this gap.

\section{The SOL Youth study}

SOL Youth is a multisite observational study funded by the National Heart, Lung, and Blood Institute to examine factors associated with childhood obesity and cardiometabolic risk among a diverse sample of Hispanic/Latino children (aged 8-16 years; $N=1600$ ) living in one of four U.S. cities (Bronx, Chicago, Miami, and San Diego; see Isasi et al., in press). The specific aims of SOL Youth are to (1) evaluate the influence of child acculturation and intergenerational differences in acculturation between children and parents on children's obesity-related behaviors and their cardiometabolic risk profiles; (2) test the association of parenting strategies and practices with children's obesity-related behaviors and cardiometabolic risk profiles; and (3) assess the influence of child psychosocial functioning on obesity-related behaviors and cardiometabolic risk profiles. Aims were informed by several theoretical frameworks relevant to childhood obesity and based on a conceptual model representing sources of influence specific to U.S. Hispanic/Latino children.

\section{Theoretical frameworks relevant to childhood obesity}

The SOL Youth study is informed predominantly by the Socio-Ecological Framework (SEF) [7,8] and Social Cognitive Theory (SCT) [9]. SEF differentiates influences as occurring at multiple levels [7], including at the individual, interpersonal, organizational, and community levels. These levels exert both direct and indirect influences on behaviors and interact with each other to influence behaviors and health outcomes. Research demonstrates associations between multiple levels of SEF and childhood obesity [10,11]. Similarly, SCT supports the concept of interactions between influences in its concept of reciprocal determinism, the dynamic interplay between a person, his/her behaviors, and the environment in which these behaviors take place [9]. Elements of the person include his/her cognitions, norms, and factors that may influence these (e.g., demographic variables). The environment includes both social and physical influences, the former best represented by personal relationships and the latter represented by the availability of healthy options in a grocery store, for 
example. There is substantial evidence supporting the association between concepts in SCT and childhood obesity [12].

Complementing both SEF and SCT are additional theoretical frameworks including Family Systems Theory (FST) $[13,14]$ and theories of acculturation [15-17]. FST posits that individuals within the family exert an influence over others, while simultaneously being influenced by the environment that is created by these interactions [18]. As such, intervention researchers have successfully targeted the family to prevent and control childhood obesity [19]. Central to the present study are the FST concepts of subsystems and levels within the family system. Among the most widely studied subsystems in childhood obesity research is the parent-children relationship [18]. A wealth of research supports the importance of parenting on childhood obesity [20]. Second, within families, there are both first- and second-order system levels. From the perspective of childhood obesity, Skelton et al. [18] argues that first-order system levels are considered primary; for example, whether families eat meals together. However, first-order system levels may not occur without the presence of second-order system levels; for example, families having the necessary time management and communication skills to facilitate family meals. This evidence dictates the need to consider both direct and indirect influences on obesity.

Finally, as defined by Berry [15] and others [17,21], acculturation refers to the process of change that occurs in language use, behaviors, social norms, and other aspects of human life with continuous, first-hand contact with a dominant ethnic group that is different from one's own. This process is considered both multidimensional (occurring on more than one cultural dimension, e.g., language and norms), as well as bidirectional. Regarding the latter and in part depending on the characteristics of the receiving community (e.g., individuals living on the U.S.-Mexico border can function without learning English), individuals may retain aspects of their original culture and thus remain traditional in their cultural orientation, they may become assimilated and lose all or most of their original culture, or they may become bicultural, retaining some aspects of their original culture and adopting new ones from their new culture. Research in acculturation provides some evidence supporting the associations between several dimensions of acculturation and Hispanic/Latino childhood obesity.

SOL Youth researchers brought these complementary lines of research to create a conceptual model (see Fig. 1) that was then used to guide selection of measures (Table 1).

\section{SOL Youth conceptual model}

\section{Individual}

At the individual level, genetic factors can influence the development of obesity and often work in concert with behavioral and environmental influences [22,23]. Behaviors such as diet [24-27], physical activity (PA) [25,28,29], and inactivity (most notably screen time) $[26,30,31]$ and short sleep duration [32] are associated with childhood obesity among U.S. Hispanic/Latino children. Nevertheless, results are not always consistent. For example, Field et al. determined that only vegetable consumption (and not fruit or juice consumption) predicted body mass index (BMI) among boys; however, this finding became nonsignificant when calories were entered into the model [33]. Similarly, in a nationally representative sample that included 36\% Hispanic/Latino children aged 2-5 years, consumption of $100 \%$ fruit juice was not associated with BMI, although it was associated with higher energy intake [34]. In a second national study involving Hispanic/Latino children, television watching was only associated with obesity among girls but not boys [35]. Consumption of breakfast has been identified as an important protective factor for obesity in an ethnically diverse sample of Hispanic/Latino children [36]. However, most studies show that a combination of risk factors is associated with a greater prevalence of obesity [25,37]. 
A second source of individual influence, not specified in previous models [38], is emotional health [39]. Emotional and behavioral difficulties are more common among Hispanic/Latino children who are overweight/obese, although gender and language of interview appear to moderate this association (e.g., findings did not hold for male boys who completed the interview in Spanish) [40]. This research is driven in part by evidence that children experience stigma associated with being overweight or obese [41]. However, causality is difficult to determine given the study designs used.

Demographic and socioeconomic indicators comprise a third and fourth source of individual influence on childhood obesity. Gender is important given the higher obesity prevalence among Hispanic/Latino boys compared with all other racial/ethnic and gender subgroups $[1,42]$. In most models, socioeconomic indicators are placed at the individual level, although they often operate at multiple levels given "the role of money" in predicting childhood obesity [43]. Caprio et al. [43] argue that the cost of food determines what one buys and there is substantial evidence that unhealthy convenience foods are less expensive than healthy foods [44]. Consumption of unhealthy convenience foods is, in turn, associated with a higher prevalence of childhood obesity in Hispanic/Latino children [45]. Similar arguments have been made for the cost of and access to PA-promoting resources [10]. Other socioeconomic indicators, such as household income, remained significantly associated with obesity in a sample of Mexican-origin children [24] and explained some of the differences observed in obesity between Hispanic/Latino and white fifth graders from three cities in the United States [46]. In one study, parent education was inversely associated with overweight among diverse adolescents [47].

\section{Interpersonal}

Our conceptual model emphasizes the role of families and parents in predicting childhood obesity risk. Families who eat breakfast together less frequently [25] or who eat while watching television have children at greater risk for obesity [48]. In a sample of Brazilian, Haitian, and other Latina mothers, those with a low demanding/high-responsive feeding style (i.e., few rules and demands, although high in warmth) had heavier children compared with those with other feeding styles [49]. Similar findings were observed by Hennessy [50] and Hughes [51]. Parents also determine what is available in the home; for example, having a television available in the bedroom was associated with obesity [48]. This is particularly troublesome among low-income families given evidence that bedrooms often serve as living rooms when several families share a home [52], a phenomenon more prevalent among immigrant families [53].

One influence that bridges the individual and interpersonal is sociocultural influence. Whether operationalized as country of birth, number of years lived in the United States, or language spoken at home, evidence is mixed on the association with childhood obesity. Nationally representative data suggest that second and third generation adolescents of diverse ethnic backgrounds are more likely to be overweight than first-generation adolescents [54]. Similar findings were observed among Mexican-American adolescents [55] and among boys who were U.S.-born or had lived in the United States for 10+ years compared with their counterparts [47]. However, after adjusting for socioeconomic status (SES), risk was higher among first-generation adolescents compared with their counterparts [56] or the association became nonsignificant [57].

Research on maternal acculturation is mixed, with some studies concluding a positive association between maternal acculturation and childhood obesity [58-60] and other evidence suggesting that children of newly arrived immigrants are more likely to be overweight than longer residing immigrants and children of U.S. natives [61,62]. Evidence is also mixed when language use is considered. Wojcicki et al. [36] found that speaking 
Spanish at home was only associated with childhood obesity among Central and South American children and not Mexican children. Sussner et al. [63] reached similar conclusions in a diverse sample of Hispanic/Latino immigrant and nonimmigrant mothers. Likewise, Van Hook and Baker [64] determined that children of non-English-speaking immigrant parents were more likely to be overweight than English-speaking immigrant parents. Ariza et al. [26], on the other hand, found no such association among Mexican families.

\section{Organizational: school}

Most research in schools is not specific to Hispanic/Latino children. National studies reporting some Hispanic/Latino student enrollment have identified a number of risk factors for obesity. For example, Fox et al. [65] determined that elementary schools that offer French fries or dessert at least once a week or more were more likely to have students who were obese. In middle schools, the presence of vending machines with energy-dense foods was associated with obesity. However, no significant associations were observed between the school food environment and obesity in high schools. Similarly, the presence of a vending machine at school was not associated with overweight among a diverse sample of adolescents in California [47]. Harrison and Jones [66] proposed a new framework for understanding physical environmental influences on childhood obesity.

\section{Community}

Childhood obesity is also influenced by community factors, including number of fast food restaurants and convenience stores proximal to the child's school [67] and lack of available supermarkets [68]. Having one or more convenience stores on one's block was associated with a greater likelihood of being obese in a sample of predominantly Hispanic/Latino children [69]. However, this same study found that density of fast food restaurants proximal to one's home was not associated with obesity. Few studies examining the PA environment and obesity have considered Hispanic/Latino children; one study in which 33\% of the sample was Hispanic/Latino identified sidewalk completeness [70] as being associated with a higher BMI $z$-score. However, the presence of a park or playground near one's home was not associated with overweight [47].

\section{Application to SOL Youth}

The conceptual model described above was used to inform the selection of study measures (see Table 1; additional details on study measures can be found in Isasi et al, in press). Highlighted next are three innovative features of the SOL Youth study and their implications for Latino family health research: collection of data from children and parents, multiple operationalizations of acculturation, and multiple operationalizations of familial/parental influences.

\section{Unique features of the SOL Youth study}

Child and parent data-An important aspect of our study design is the collection of data from both the child and the parent/caregiver, including biological and self-reported data. Blood samples and other objective measures will allow us to examine the heritability of obesity risk. Administration of the same self-report scales with both the child and parent will allow us to conduct dyadic analyses [71-73], a more refined approach to examining the bidirectional influences of children and parents.

Acculturation and intergenerational differences-Selected strategies to measure acculturation reflect our interest in examining this variable from an individual and an interpersonal perspective. The 12-item brief Bauman scale was derived from the 24-item Marin scale [21] and has good psychometric properties [74]; however, it focuses exclusively 
on language use. To capture nonlanguageebased acculturation, we are administering the 8item AHISMA scale because it captures changes in social relationships [75]. In addition to acculturation, ethnic identity is being measured with the 8-item Ethnic Affirmation and Belonging scale [76], plus two questions on race/ethnicity. The former is important to better understand the potential protective effects of staying connected to one's ethnicity/culture of origin or that of one's family [77]. In addition, we are measuring stress associated with the premigration, migration, and postmigration experiences [78]. Two questions assess what the migration experience was like for the child, including how stressful it was. Acculturative stress is one's experience with the acculturation process, how well one adapts to the changes that are occurring, some of which are not under one's control. We are measuring this concept using the 9-item Acculturative Stress scale [79].

Using these scales, we will examine intergenerational differences in acculturation and whether this places the child at greater risk for engaging in unhealthy behaviors and subject to worse health outcomes. We will test the child-parent differences using several methods, including computing a discrepancy score between the children's and parents' acculturation scores and examining whether these discrepancies are associated with a variety of health behaviors and health outcomes relevant to obesity. Importantly, given evidence that SES is often neglected in previous analyses examining the association between acculturation and health [80], these models will consider the many dimensions of SES captured in our protocol (see Table 1).

Family and parenting-A limitation of much of the research on families and parents is the exclusive use of measures that assess family influences and parenting specific to obesigenic behaviors. Although specificity is important for measurement [9], exclusive use of these measures without a concurrent assessment of general family functioning and parenting does not permit one to disentangle the unique variance associated with diseasespecific family functioning and parenting. This design element of the SOL Youth study will allow us to fill a gap in this research [18].

Our protocol captures family functioning with 12 questions [81] and family closeness with seven questions [82] from both the perspective of the child and that of the parent. In addition, parents respond to a 5-item Familismo scale [83] to better understand family members' sense of obligation to each other, a concept that is culturally relevant to the target population [84]. Family support for fruit and vegetable intake is being measured with four questions developed by Norman et al. [85] and similar questions assess family support for PA [86]. Several discrete indicators of family influences are being captured specific to eating, including how often the family eats dinner in front of the television [87], how often they consume meals together [87], and where they shop for groceries [88]; all these activities have been identified as factors associated with food consumption, and ultimately, risk for obesity. To measure general parenting, we are using the 16-item authoritative parenting scale [89]. To measure parenting related to diet and PA, we are using the 26-item Parenting Strategies for Eating and Activity Scale scale [90]. In the Parenting Strategies for Eating and Activity Scale validation study, parents who set more limits with their children had children who were at lower risk of being obese [90].

Other considerations-The inclusion of children and parents from several Hispanic/ Latino backgrounds, including Cuban-, Puerto Rican-, and other Central- and South American-origin children, in addition to Mexican, will allow us to assess the generalizability of multilevel models previously tested only with those of Mexican origin [59] to include other Hispanic/Latino backgrounds. 


\section{Conclusions}

SOL Youth is an innovative study examining factors associated with childhood obesity and cardiometabolic risk. Using several well-established theoretical frameworks, SOL Youth investigators created a conceptual model to inform several study design features, as well as contextually and culturally relevant measurement approaches to the collection of measured and self-reported data.

\section{Limitations}

Models for understanding childhood obesity and cardiometabolic risk should consider aspects at multiple levels of influence. In the SOL Youth study, we are examining risk and protective factors at four levels of influence; however, our assessments of the organizational and community levels are measured via child- and parent-reported perceptions. Ideally, school and community influences would be collected via direct observation [91] or using existing databases (e.g., enumerating types of grocery stores in the neighborhood) [92]. This research would complement the SOL Youth study given differences identified in the types of foods that are available depending on where a family does most of their grocery shopping [88]. An ability to develop linkages with directly collected environmental data would strengthen conclusions that could be drawn from this study. Unfortunately, such data collection was beyond the scope and budget of this study. Second, to maximize recruitment of 1600 children, we are allowing more than one child per household to participate. This introduces possible clustering of data within households; however, we can compensate for this intraclass correlation in statistical analyses by nesting children in households. At the same time, having multiple children in a household will allow for dyadic analyses with different children to determine whether observed relationships are consistent across children in the same household. Finally, given the design of the larger SOL Youth study, site is confounded with Hispanic/Latino subgroup and the rural context is missing. Regarding the former point, the San Diego and Miami sites have a more homogenous Hispanic/Latino sample (Mexican and Cuban, respectively), making it more difficult to disentangle site and Hispanic/Latino subgroup.

\section{Informing future research and practice}

Although there have been calls for studies to identify "aggressive approaches for the prevention and treatment" of childhood obesity, there remains a dearth of research examining what factors are most relevant to address this epidemic. SOL Youth hopes to fill a gap in this research by testing a comprehensive model linking individual, interpersonal, school, and community data to better understand risk and protective factors associated with childhood obesity and cardiometabolic status among U.S. Latino children.

\section{Acknowledgments}

The SOL Youth study was supported by grant number R01HL102130 from the National Heart, Lung, And Blood Institute (NHLBI). The children in SOL Youth are drawn from the study of adults: The Hispanic Community Health Study/Study of Latinos, which was supported by contracts from NHLBI to the University of North Carolina (N01-HC65233), University of Miami (N01-HC65234), Albert Einstein College of Medicine (N01-HC65235), Northwestern University (N01-HC65236), and San Diego State University (N01-HC65237). The following Institutes/Centers/Offices contribute to the HCHS/SOL through a transfer of funds to NHLBI: National Center on Minority Health and Health Disparities, the National Institute of Deafness and Other Communications Disorders, the National Institute of Dental and Craniofacial Research, the National Institute of Diabetes and Digestive and Kidney Diseases, the National Institute of Neurological Disorders and Stroke, and the Office of Dietary Supplements. The content is solely the responsibility of the authors and does not necessarily represent the official views of NHLBI or the National Institutes of Health. 


\section{References}

1. Ogden CL, Carroll MD, Kit BK, Flegal KM. Prevalence of obesity and trends in body mass index among US children and adolescents, 1999-2010. JAMA. 2012; 307:483-90. [PubMed: 22253364]

2. Filozof C, Gonzalez C, Sereday M, Mazza C, Braguinsky J. Obesity prevalence and trends in LatinAmerican countries. Obes Rev. 2001; 2:99-106. [PubMed: 12119667]

3. Freedman DS, Khan LK, Serdula MK, Dietz WH, Srinivasan SR, Berenson GS. Racial differences in the tracking of childhood BMI to adulthood. Obes Res. 2005; 13:928-35. [PubMed: 15919847]

4. Liese AD, D'Agostino RB, Hamman RF, Kilgo PD, Lawrence JM, Liu LL, et al. The burden of diabetes mellitus among US youth: prevalence estimates from the SEARCH for Diabetes in Youth Study. Pediatrics. 2006; 118:1510-8. [PubMed: 17015542]

5. Schwimmer JB, Burwinkle TM, Varni JW. Health-related quality of life of severely obese children and adolescents. JAMA. 2003; 289:1813-9. [PubMed: 12684360]

6. Park MH, Falconer C, Viner RM, Kinra S. The impact of childhood obesity on morbidity and mortality in adulthood: a systematic review. Obes Rev. 2012; 13:985-1000. [PubMed: 22731928]

7. Stokols D. Translating social ecological theory into guidelines for community health promotion. Am J Health Promot. 1996; 10:282-98. [PubMed: 10159709]

8. Bronfenbrenner, U. The ecology of human development: experiments by nature and design. Harvard University Press; Cambridge, MA: 1979.

9. Bandura, A. Social foundations of thought and action: a Social Cognitive Theory. Prentice-Hall; Englewood Cliffs, N.J: 1986.

10. Maziak W, Ward K, Stockton M. Childhood obesity: are we missing the big picture? Obes Rev. 2008; 9:35-42. [PubMed: 18154601]

11. Kumanyika SK. Environmental influences on childhood obesity: ethnic and cultural influences in context. Physiol Behav. 2008; 94:61-70. [PubMed: 18158165]

12. Sosa ET. Mexican American mothers' perceptions of childhood obesity: a theory-guided systematic literature review. Health Educ Behav. 2012; 39:396-404. [PubMed: 21551423]

13. Broderick, C. Understanding family process: basics of Family Systems Theory. SAGE Publications; Newbury Park, CA: 1993.

14. White, JM.; Klein, DM. The systems framework. Family theories. SAGE Publications; Thousand Oaks, CA: 2007.

15. Berry, JW. Conceptual approaches to acculturation.. In: Chun, KM.; Organista, PB.; Marín, G., editors. Acculturation: advances in theory, measurement, and applied research. American Psychological Association; Washington, DC: 2003. p. 17-37.

16. Abraído-Lanza AF, Armbrister AN, Flórez KR, Aguirre AN. Toward a theory-driven model of acculturation in public health research. Am J Public Health. 2006; 96:1342-6. [PubMed: 16809597]

17. Cuéllar IA, Maldonado Bill, Roberto. Acculturation Rating Scale for Mexican Americans-II: a revision of the original ARSMA scale. Hispanic J Behav Sci. 1995; 17:275-304.

18. Skelton JA, Buehler C, Irby MB, Grzywacz JG. Where are family theories in family-based obesity treatment?: conceptualizing the study of families in pediatric weight management. Int J Obes (Lond). 2012; 36:891-900. [PubMed: 22531090]

19. Berge JM, Everts JC. Family-based interventions targeting childhood obesity: a meta-analysis. Child Obes. 2011; 7:110-21.

20. Ventura A, Birch L. Does parenting affect children's eating and weight status? Int J Behav Nutr Phys Act. 2008; 5:15. [PubMed: 18346282]

21. Marín G, Gamba RJ. A new measurement of acculturation for Hispanics: the Bidimensional Acculturation Scale for Hispanics (BAS). Hispanic J Behav Sci. 1996; 18:297-316.

22. Fernandez JR, Klimentidis YC, Dulin-Keita A, Casazza K. Genetic influences in childhood obesity: recent progress and recommendations for experimental designs. Int J Obes (Lond). 2012; 36:479-84. [PubMed: 22158269] 
23. Butte NF, Cai G, Cole SA, Comuzzie AG. Viva la Familia Study: genetic and environmental contributions to childhood obesity and its comorbidities in the Hispanic population. Am J Clin Nutr. 2006; 84:646-54. quiz 73-4. [PubMed: 16960181]

24. Melgar-Quiñonez HR, Kaiser LL. Relationship of child-feeding practices to overweight in lowincome Mexican-American preschool-aged children. J Am Diet Assoc. 2004; 104:1110-9. [PubMed: 15215770]

25. Carlson J, Crespo N, Patterson R, Sallis J, Elder J. Dietary-related and physical activity-related predictors of obesity in children: a 2-yr prospective study. Child Obes. 2012; 8:110-5. [PubMed: 22799510]

26. Ariza AJ, Chen EH, Binns HJ, Christoffel KK. Risk factors for overweight in fiveto six-year-old Hispanic-American children: a pilot study. J Urban Health. 2004; 81:150-61. [PubMed: 15047793]

27. Davis JN, Whaley SE, Goran MI. Effects of breastfeeding and low sugar-sweetened beverage intake on obesity prevalence in Hispanic toddlers. Am J Clin Nutr. 2012; 95:3-8. [PubMed: 22170357]

28. Andersen R, Crespo C, Bartlett S, Cheskin L, Pratt M. Relationship of physical activity and television watching with body weight and level of fatness among children: results from the Third National Health and Nutrition Examination Survey. JAMA. 1998; 279:938-42. [PubMed: 9544768]

29. Butte NF, Cai G, Cole SA, Wilson TA, Fisher JO, Zakeri IF, et al. Metabolic and behavioral predictors of weight gain in Hispanic children: the Viva la Familia Study. Am J Clin Nutr. 2007; 85:1478-85. [PubMed: 17556682]

30. Giammattei J, Blix G, Marshak HH, Wollitzer AO, Pettitt DJ. Television watching and soft drink consumption: associations with obesity in 11- to 13-year-old schoolchildren. Arch Pediatr Adolesc Med. 2003; 157:882-6. [PubMed: 12963593]

31. Singh GK, Kogan MD, Van Dyck PC, Siahpush M. Racial/ethnic, socioeconomic, and behavioral determinants of childhood and adolescent obesity in the United States: analyzing independent and joint associations. Ann Epidemiol. 2008; 18:682-95. [PubMed: 18794009]

32. Liu J, Zhang A, Li L. Sleep duration and overweight/obesity in children: review and implications for pediatric nursing. J Spec Pediatr Nurs. 2012; 17:193-204. [PubMed: 22734873]

33. Field AE, Gillman MW, Rosner B, Rockett HR, Colditz GA. Association between fruit and vegetable intake and change in body mass index among a large sample of children and adolescents in the United States. Int J Obes Relat Metab Disord. 2003; 27:821-6. [PubMed: 12821968]

34. O'Connor TM, Yang SJ, Nicklas TA. Beverage intake among preschool children and its effect on weight status. Pediatrics. 2006; 118:e1010-8. [PubMed: 17015497]

35. Crespo C, Smit E, Troiano R, Bartlett S, Macera C, Andersen R. Television watching, energy intake, and obesity in US children: results from the third National Health and Nutrition Examination Survey, 1988-1994. Arch Pediatr Adolesc Med. 2001; 155:360-5. [PubMed: 11231802]

36. Wojcicki JM, Schwartz N, Jiménez-Cruz A, Bacardi-Gascon M, Heyman MB. Acculturation, dietary practices and risk for childhood obesity in an ethnically heterogeneous population of Latino school children in the San Francisco bay area. J Immigr Minor Health. 2012; 14:533-9. [PubMed: 22101726]

37. Tanasescu M, Ferris AM, Himmelgreen DA, Rodriguez N, Pérez-Escamilla R. Biobehavioral factors are associated with obesity in Puerto Rican children. J Nutr. 2000; 130:1734-42. [PubMed: 10867044]

38. Davison KK, Birch LL. Childhood overweight: a contextual model and recommendations for future research. Obes Rev. 2001; 2:159-71. [PubMed: 12120101]

39. Scheimann AO. Overview of paediatric obesity for the paediatric mental health provider. Int Rev Psychiatry. 2012; 24:231-40. [PubMed: 22724644]

40. Pastor PN, Reuben CA. Emotional/behavioral difficulties and adolescent obesity: effect of sex and Hispanic origin/race. Int J Pediatr Obes. 2011; 6:462-6. [PubMed: 21790263]

41. Puhl RM, Latner JD. Stigma, obesity, and the health of the nation's children. Psychol Bull. 2007; 133:557-80. [PubMed: 17592956] 
42. Winham DM. Growth status among low-income Mexican and Mexican-American elementary school children. Am J Hum Biol. 2012; 24:690-5. [PubMed: 22836381]

43. Caprio S, Daniels SR, Drewnowski A, Kaufman FR, Palinkas LA, Rosenbloom AL, et al. Influence of race, ethnicity, and culture on childhood obesity: implications for prevention and treatment: a consensus statement of Shaping America's Health and the Obesity Society. Diabetes Care. 2008; 31:2211-21. [PubMed: 18955718]

44. Monsivais P, Drewnowski A. The rising cost of low-energy-density foods. J Am Diet Assoc. 2007; 107:2071-6. [PubMed: 18060892]

45. Ayala G, Rogers M, Arredondo E, Campbell N, Baquero B, Duerksen S, et al. Away-from-home food intake and risk for obesity: examining the influence of context. Obesity (Silver Spring). 2008; 16:1002-8. [PubMed: 18309297]

46. Schuster MA, Elliott MN, Kanouse DE, Wallander JL, Tortolero SR, Ratner JA, et al. Racial and ethnic health disparities among fifth-graders in three cities. N Engl J Med. 2012; 367:735-45. [PubMed: 22913683]

47. Ahn MK, Juon HS, Gittelsohn J. Association of race/ethnicity, socioeconomic status, acculturation, and environmental factors with risk of overweight among adolescents in California, 2003. Prev Chronic Dis. 2008; 5:A75. [PubMed: 18558025]

48. Dennison BA, Erb TA, Jenkins PL. Television viewing and television in bedroom associated with overweight risk among low-income preschool children. Pediatrics. 2002; 109:1028-35. [PubMed: 12042539]

49. Tovar A, Hennessy E, Pirie A, Must A, Gute DM, Hyatt RR, et al. Feeding styles and child weight status among recent immigrant mother-child dyads. Int J Behav Nutr Phys Act. 2012; 9:62. [PubMed: 22642962]

50. Hennessy E, Hughes SO, Goldberg JP, Hyatt RR, Economos CD. Parent behavior and child weight status among a diverse group of underserved rural families. Appetite. 2010; 54:369-77. [PubMed: 20079785]

51. Hughes SO, Shewchuk RM, Baskin ML, Nicklas TA, Qu H. Indulgent feeding style and children's weight status in preschool. J Dev Behav Pediatr. 2008; 29:403-10. [PubMed: 18714209]

52. Maitland C, Stratton G, Foster S, Braham R, Rosenberg M. A place for play? The influence of the home physical environment on children's physical activity and sedentary behaviour. Int J Behav Nutr Phys Act. 2013; 10:99. [PubMed: 23958282]

53. Taylor, P.; Passel, J.; Fry, R.; Morin, R.; Wang, W.; Velasco, G., et al. The return of the multigenerational family household. Pew Research Center; Washington, DC: Mar. 2010

54. Harris KM, Perreira KM, Lee D. Obesity in the transition to adulthood: predictions across race/ ethnicity, immigrant generation, and sex. Arch Pediatr Adolesc Med. 2009; 163:1022-8. [PubMed: 19884593]

55. Liu JH, Chu YH, Frongillo EA, Probst JC. Generation and acculturation status are associated with dietary intake and body weight in Mexican American adolescents. J Nutr. 2012; 142:298-305. [PubMed: 22223572]

56. Gordon-Larsen P, Adair LS, Popkin BM. The relationship of ethnicity, socioeconomic factors, and overweight in US adolescents. Obes Res. 2003; 11:121-9. [PubMed: 12529494]

57. Liu J, Probst JC, Harun N, Bennett KJ, Torres ME. Acculturation, physical activity, and obesity among Hispanic adolescents. Ethn Health. 2009; 14:509-25. [PubMed: 19404878]

58. Fuentes-Afflick E, Hessol NA. Overweight in young Latino children. Arch Med Res. 2008; 39:511-8. [PubMed: 18514096]

59. Elder J, Arredondo E, Campbell N, Baquero B, Duerksen S, Ayala G, et al. Individual, family, and community environmental correlates of obesity in Latino elementary school children. J Sch Health. 2010; 80:20-30. quiz 53-5. [PubMed: 20051087]

60. Hernández-Valero MA, Wilkinson AV, Forman MR, Etzel CJ, Cao Y, Bárcenas CH, et al. Maternal BMI and country of birth as indicators of childhood obesity in children of Mexican origin. Obesity (Silver Spring). 2007; 15:2512-9. [PubMed: 17925478]

61. Baker E, Balistreri KS, Van Hook J. Maternal employment and overweight among Hispanic children of immigrants and children of natives. J Immigr Minor Health. 2009; 11:158-67. [PubMed: 17963041] 
62. Balistreri KS, Van Hook J. Socioeconomic status and body mass index among Hispanic children of immigrants and children of natives. Am J Public Health. 2009; 99:2238-46. [PubMed: 19846690]

63. Sussner KM, Lindsay AC, Peterson KE. The influence of maternal acculturation on child body mass index at age 24 months. J Am Diet Assoc. 2009; 109:218-25. [PubMed: 19167948]

64. Van Hook J, Baker E. Big boys and little girls: gender, acculturation, and weight among young children of immigrants. J Health Soc Behav. 2010; 51:200-14. [PubMed: 20617759]

65. Fox MK, Dodd AH, Wilson A, Gleason PM. Association between school food environment and practices and body mass index of US public school children. J Am Diet Assoc. 2009; 109:S10817. [PubMed: 19166665]

66. Harrison F, Jones AP. A framework for understanding school based physical environmental influences on childhood obesity. Health Place. 2012; 18:639-48. [PubMed: 22281440]

67. Powell LM, Auld MC, Chaloupka FJ, O'Malley PM, Johnston LD. Associations between access to food stores and adolescent body mass index. Am J Prev Med. 2007; 33:S301-7. [PubMed: 17884578]

68. Liu GC, Wilson JS, Qi R, Ying J. Green neighborhoods, food retail and childhood overweight: differences by population density. Am J Health Promot. 2007; 21:317-25. [PubMed: 17465177]

69. Galvez MP, Hong L, Choi E, Liao L, Godbold J, Brenner B. Childhood obesity and neighborhood food-store availability in an inner-city community. Acad Pediatr. 2009; 9:339-43. [PubMed: 19560992]

70. Duncan DT, Castro MC, Gortmaker SL, Aldstadt J, Melly SJ, Bennett GG. Racial differences in the built environmentdbody mass index relationship? A geo-spatial analysis of adolescents in urban neighborhoods. Int J Health Geogr. 2012; 11:11. [PubMed: 22537116]

71. Lewis MA, McBride CM, Pollak KI, Puleo E, Butterfield RM, Emmons KM. Understanding health behavior change among couples: an interdependence and communal coping approach. Soc Sci Med. 2006; 62:1369-80. [PubMed: 16146666]

72. Lewis MA, Butterfield RM. Social control in marital relationships: effect of one's partner on health behaviors. J Appl Soc Psychol. 2007; 37:289-319.

73. Campbell L, Kashy DA. Estimating actor, partner, and interaction effects for dyadic data using PROC MIXED and HLM: a userefriendly guide. Pers Relationship. 2002; 9:327-42.

74. Bauman S. The reliability and validity of the Brief Acculturation Rating Scale for Mexican Americans-II for children and adolescents. Hisp J Behav Sci. 2005; 27:426-41.

75. Unger JB, Gallahen P, Shakib S, Ritt-Olson A, Palmer PH, Johnson CA. The AHIMSA Acculturation Scale: a new measure of acculturation for adolescents in a multicultural society. $\mathrm{J}$ Early Adolescence. 2002; 22:225-51.

76. Phinney JS. The Multigroup Ethnic Identity Measure: a new scale for use with diverse groups. J Adolescent Res. 1992; 7:156-76.

77. Lorenzo-Blanco EI, Unger JB, Baezconde-Garbanati L, Ritt-Olson A, Soto D. Acculturation, enculturation, and symptoms of depression in Hispanic youth: the roles of gender, Hispanic cultural values, and family functioning. J Youth Adolesc. 2012; 41:1350-65. [PubMed: 22627624]

78. Perreira KM, Ornelas IJ. The physical and psychological well-being of immigrant children. Future Child. 2011; 21:195-218. [PubMed: 21465861]

79. Gil AG, Vega WA, Dimas JM. Acculturative stress and personal adjustment among Hispanic adolescent boys. J Community Psychol. 1994; 22:43-54.

80. Hunt LM, Schneider S, Comer B. Should "acculturation" be a variable in health research? A critical review of research on US Hispanics. Soc Sci Med. 2004; 59:973-86. [PubMed: 15186898]

81. Aarons GA, McDonald EJ, Connelly CD, Newton RR. Assessment of family functioning in Caucasian and Hispanic Americans: reliability, validity, and factor structure of the Family Assessment Device. Fam Process. 2007; 46:557-69. [PubMed: 18092586]

82. Kapinus CA, Corman BK. Closeness with parents and perceived consequences of pregnancy among male and female adolescents. Sociol Quart. 2004; 45:691-717.

83. Steidel AGL, Contreras JM. A new familism scale for use with Latino populations. Hispanic J Behav Sci. 2003; 25:312-30. 
84. Elder J, Ayala G, Parra-Medina D, Talavera G. Health communication in the Latino community: issues and approaches. Annu Rev Public Health. 2009; 30:227-51. [PubMed: 19296776]

85. Norman GJ, Carlson JA, Sallis JF, Wagner N, Calfas KJ, Patrick K. Reliability and validity of brief psychosocial measures related to dietary behaviors. Int J Behav Nutr Phys Act. 2010; 7:56. [PubMed: 20594360]

86. Norman GJ, Sallis JF, Gaskins R. Comparability and reliability of paper- and computer-based measures of psychosocial constructs for adolescent physical activity and sedentary behaviors. Res Q Exerc Sport. 2005; 76:315-23. [PubMed: 16270708]

87. Andaya A, Arredondo E, Alcaraz J, Lindsay S, Elder J. The association between family meals, TV viewing during meals, and fruit, vegetables, soda, and chips intake among Latino children. J Nutr Educ Behav. 2010; 43:308-15. [PubMed: 20965787]

88. Emond JA, Madanat HN, Ayala GX. Do Latino and non-Latino grocery stores differ in the availability and affordability of healthy food items in a low-income, metropolitan region? Public Health Nutr. 2012; 15:360-9. [PubMed: 21733278]

89. Jackson C, Henriksen L, Foshee VA. The Authoritative Parenting Index: predicting health risk behaviors among children and adolescents. Health Educ Behav. 1998; 25:319-37. [PubMed: 9615242]

90. Larios S, Ayala G, Arredondo E, Baquero B, Elder J. Development and validation of a scale to measure Latino parenting strategies related to children's obesigenic behaviors. The Parenting Strategies for Eating and Activity Scale (PEAS). Appetite. 2009; 52:166-72. [PubMed: 18845197]

91. McKenzie TL. Observational measures of children's physical activity. J Sch Health. 1991; 61:2247. [PubMed: 1943048]

92. Wang MC, Gonzalez AA, Ritchie LD, Winkleby MA. The neighborhood food environment: sources of historical data on retail food stores. Int J Behav Nutr Phys Act. 2006; 3:15. [PubMed: $16846518]$ 


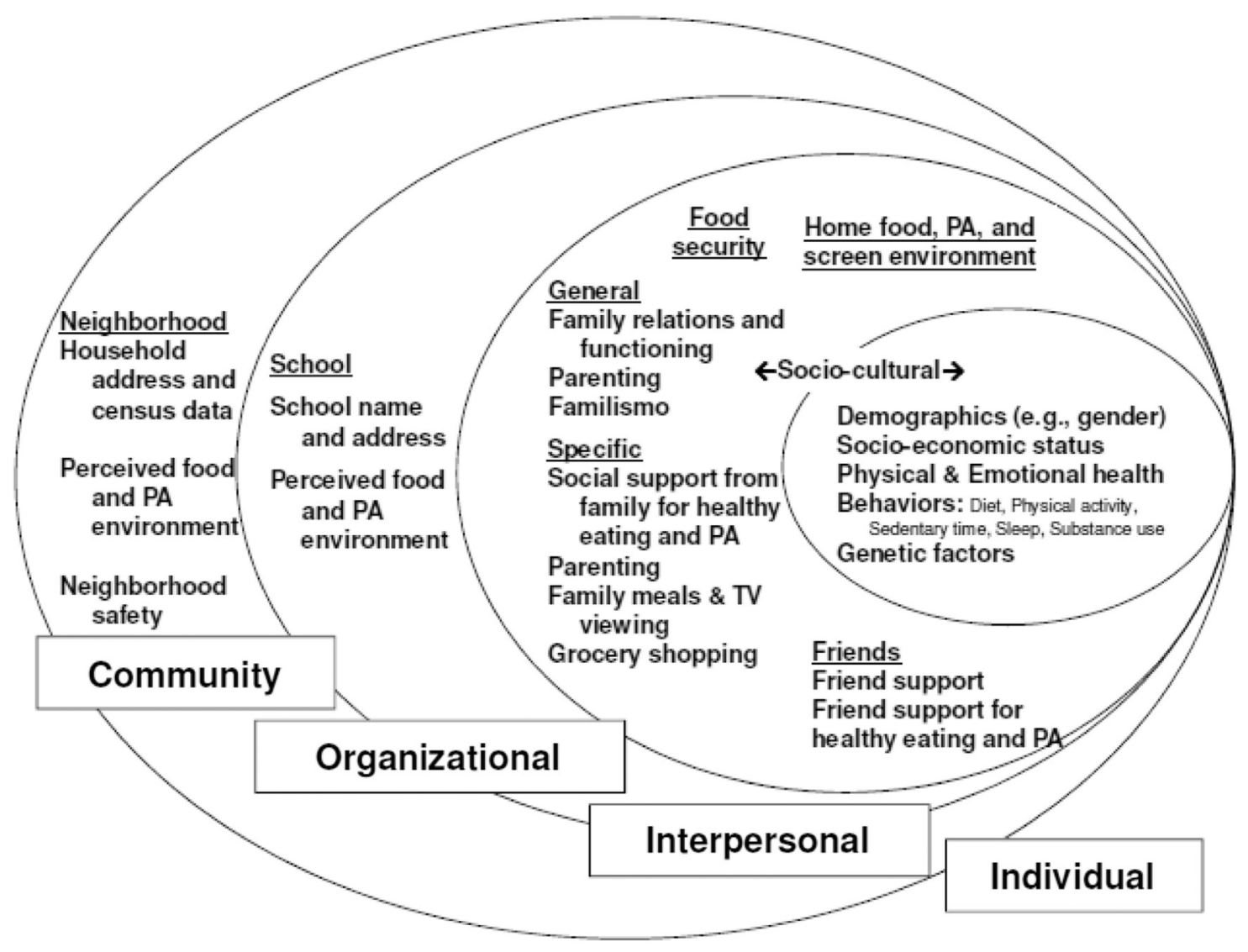

Figure 1.

Conceptual model for SOL Youth: Understanding risk and protective factors for Latino childhood obesity. 


\section{Table 1}

Measurement items organized by level of influence

\begin{tabular}{|c|c|}
\hline Constructs & Measurement approach \\
\hline Individual Demographic & $\begin{array}{l}\text { Child report: } \\
\text { • Gender (1Q; categories) } \\
\text { • Social desirability (9Qs; yes/no) } \\
\text { Parent report on self/family: } \\
\text { • Birthday (1Q; open) } \\
\text { • Gender (1Q; categories) } \\
\text { - Current marital status and if lives with spouse (2Qs; categories, yes/no) } \\
\text { • Household size (4Qs; open) } \\
\text { Parent report on spouse: } \\
\text { - Birthday (1Q; open) } \\
\text { • Gender (1Q; categories) } \\
\text { • Relationship to child (1Q; categories) }\end{array}$ \\
\hline Child socio-economic status & $\begin{array}{l}\text { Child report: } \\
\text { - Allowance given (1Q; open) } \\
\text { • Hours worked in a typical week during summer and nonsummer months (2Qs; open) } \\
\text { Parent report on child: } \\
\text { - Child's health insurance and lack of coverage (5Qs; varied) } \\
\text { - Medical home (2Qs; varied) } \\
\text { - Grade in school, type of school, and school attendance (5Qs; varied) } \\
\text { Parent report on self/family: } \\
\text { - Parent health insurance and lack of coverage (5Qs; varied) } \\
\text { - Employment (5Qs; varied) } \\
\text { - Education (1Q: } 1 \text { = never or kindergarten to } 10=\text { professional training beyond a 4-y college or university) } \\
\text { - Other assets (13Qs; yes/no) } \\
\text { - Food assistance (6Qs; yes/no) } \\
\text { - Income and number it supports (4Qs; varied) } \\
\text { - Type of dwelling (1Q; } 1 \text { = house to } 5 \text { = trailer home) } \\
\text { - Motor vehicles (1Q; open) } \\
\text { - Economic hardships (5Qs; yes/no) } \\
\text { Parent report on spouse: } \\
\text { - Employment (4Qs; varied) }\end{array}$ \\
\hline Child socio-cultural & $\begin{array}{l}\text { Child report: } \\
\text { - Race/ethnicity (1Q; categorical) } \\
\text { - Hispanic/Latino background (1Q; categorical) } \\
\text { - Acculturation scale (ARSMAII Brief; } 12 \mathrm{Qs} ; 1=\text { not at all to } 5=\text { almost always) } \\
\text { - Acculturation scale (AHISMA, } 8 \mathrm{Q} ; 1=\mathrm{US} \text { to } 4=\text { Neither) } \\
\text { - Ethnic affirmation and belonging (8Qs; } 1=\text { strongly disagree to } 5=\text { strongly agree) } \\
\text { - Acculturative stress (9Qs; } 1=\text { not at all to } 5=\text { almost always) } \\
\text { - Country of birth (1Q; categorical) }\end{array}$ \\
\hline
\end{tabular}




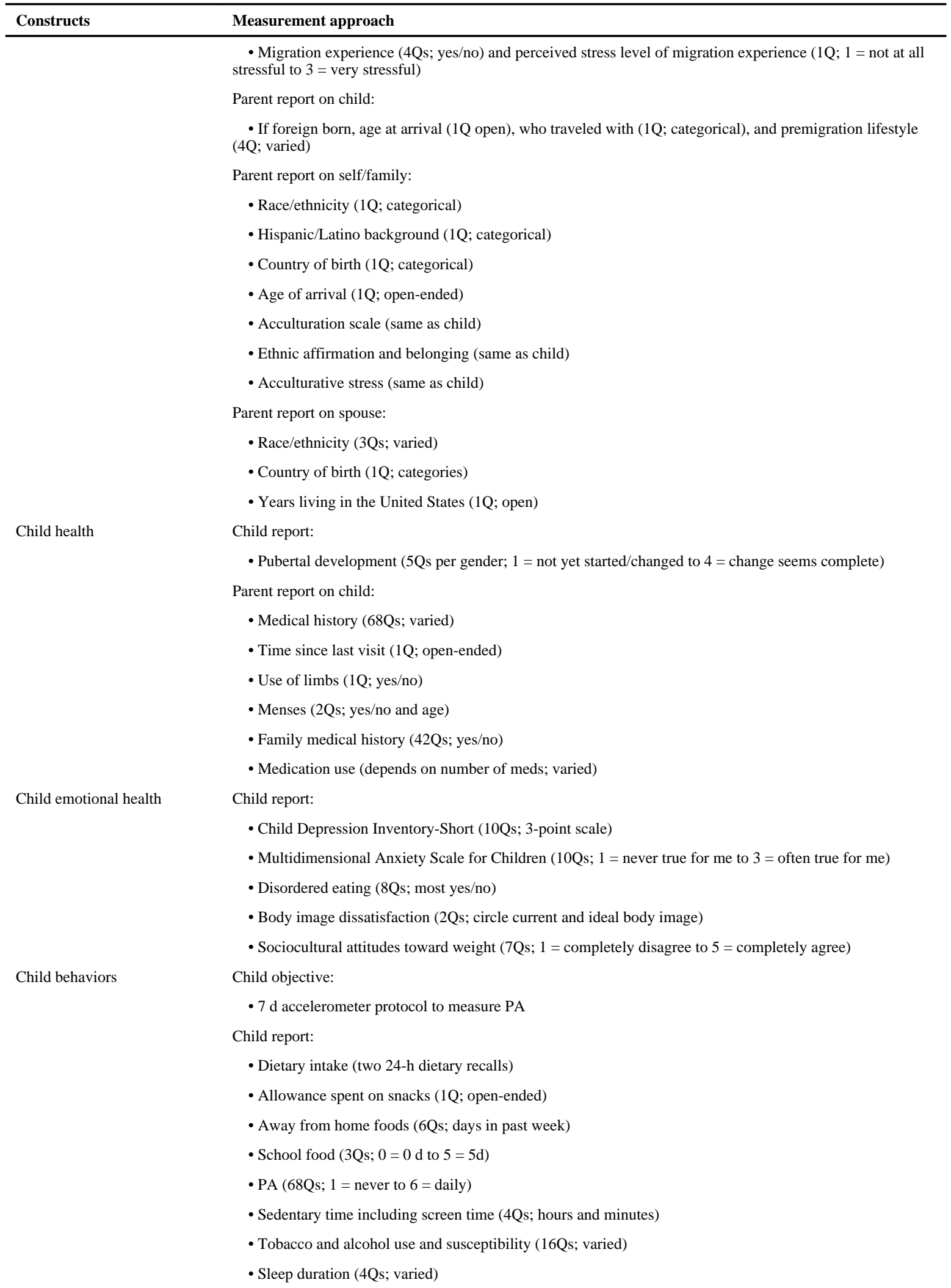




\begin{tabular}{|c|c|}
\hline Constructs & Measurement approach \\
\hline $\begin{array}{l}\text { Interpersonal General family } \\
\text { relations }\end{array}$ & $\begin{array}{l}\text { - Family functioning (12Qs; } 1 \text { = strongly agree to } 4=\text { strongly disagree) } \\
\text { - Family relationships including closeness (7Qs; various); } \\
\text { Parent report on child: } \\
\text { - Relationships ( } 20 \mathrm{Qs} \text {; varied) } \\
\text { - Authoritative parenting (16Qs; } 1 \text { = not like me to } 4=\text { just like me) } \\
\text { Parent report on self/family: } \\
\text { - Family functioning (same as child) } \\
\text { - Familismo (5Qs; } 1 \text { = strongly disagree to } 5=\text { strongly agree) }\end{array}$ \\
\hline $\begin{array}{l}\text { Family behaviors to health } \\
\text { behaviors }\end{array}$ & $\begin{array}{l}\text { Child report: } \\
\text { - Family support for fruit and vegetable intake and PA ( } 8 \mathrm{Qs} ; 1=\text { never to } 5=\text { everyday) } \\
\text { - Parenting strategies to promote eating and PA ( } 26 \mathrm{Qs} ; 1=\text { disagree or never to } 5=\text { agree or always) } \\
\text { - Eating dinner and snacks in front of the TV (2Qs; } 0=\text { never to } 4=\text { everyday) } \\
\text { Parent report on self/family: } \\
\text { - Days family meals together ( } 3 \mathrm{Qs} ; \text { open) } \\
\text { - Grocery shopping locations ( } 5 \mathrm{Q} \text {; } 11=\text { never to } 5=\text { always) } \\
\text { - Food insecurity (United States Department of Agriculture } 18 \mathrm{Qs} ; \text { varied) } \\
\text { - Parenting strategies to promote eating and PA ( } 26 \mathrm{Qs} ; 1=\text { disagree or never to } 5=\text { agree or always) }\end{array}$ \\
\hline Friend support & $\begin{array}{l}\text { Child report: } \\
\text { - General friend support (4Qs; } 1=\text { strongly disagree to } 4=\text { strongly agree) } \\
\text { - Friend support for fruit and vegetable intake and PA (8Qs; } 1=\text { never to } 5=\text { everyday) }\end{array}$ \\
\hline Home environment & $\begin{array}{l}\text { Child report: } \\
\text { - Workout equipment at home (11Qs; } 0=\text { not available to } 4=\text { once a week or more }) \\
\text { Parent report on self/family: } \\
\text { - Food in the home (17Qs; } 1=\text { never to } 5=\text { always }) \\
\text { - Televisions and electronic devices in the home (7Qs; total number of each and number in child's } \\
\text { bedroom) }\end{array}$ \\
\hline School Food environment & $\begin{array}{l}\text { Child report: } \\
\text { - Nutrition information sent home (1Q; } 0=\text { never to } 4=\text { always) } \\
\text { - Vending machines (8Qs; varied) } \\
\text { - Salad bars (2Qs; yes/no and days per week use) } \\
\text { - Carts and trucks (2Qs; same as salad bars) } \\
\text { - Brand-name fast foods available (2Qs; same as salad bars) } \\
\text { - Off campus lunch permitted (2Qs; same as salad bars) }\end{array}$ \\
\hline PA environment & $\begin{array}{l}\text { Child report: } \\
\text { - After school PA environment ( } 2 \mathrm{Q} ; 11=\text { never to } 5=\text { always })\end{array}$ \\
\hline Community Neighborhood saf & $\begin{array}{l}\text { y Parent report on self/family: } \\
\text { • Neighborhood safety ( } 5 \mathrm{Qs} ; 1=\text { not a problem to } 3=\text { major problem) }\end{array}$ \\
\hline Food environment & $\begin{array}{l}\text { Parent report on self/family: } \\
\text { • Perceived food environment ( } 5 \mathrm{Qs} ; 1=\text { strongly disagree to } 5=\text { strongly agree })\end{array}$ \\
\hline PA environment & $\begin{array}{l}\text { Parent report on self/family: } \\
\text { - Barriers to PA in the community ( } 9 \mathrm{Q} ; 11=\text { strongly disagree to } 4=\text { strongly agree })\end{array}$ \\
\hline
\end{tabular}

